\title{
Classification and determination of working area of concrete placing booms
}

\author{
Yevgeny Koshkarev * \\ Moscow State University of Civil Engineering, Yaroslavskoe shosse, 26, Moscow, 129337, Russia
}

\begin{abstract}
A concrete placing boom is the final element of concrete mixture pipeline transportation system. It is designed to deliver the concrete mixture for discharging where and when required, therefore, similar to cranes, it must be equipped with at least two mechanisms: boom extension and rotation. The mechanisms can be both manually and hydraulically actuated, hence, booms are differentiated between mechanical (manually controlled) and hydraulically or electrically controlled. This article aims at describing the areas for using various categories of concrete placing booms.
\end{abstract}

\section{Introduction}

The boom that ensures concrete mixture distribution and placing is a critical element of concreting process. The use of such equipment in modern cast-in-place technology is constantly growing. At the moment, concrete placing booms produced by the industry and applied in construction are divided into three main classes (Fig. 1):

- mechanical rotary booms;

- self-propelled, truck mounted booms (typically referred to as concrete pump trucks) or crawler-mounted;

- installed on a mast, tower or column.

\section{Mechanical rotary concrete-placing booms}

Booms of first class are used for centralized supply of concrete mixture via a concreteconveying pipe fixed on the machine as a part of its load-carrying structure, and connected with the concrete pump by a stationary pipeline $[1,2]$. Mechanical booms are placed in the required location with a crane and are ready for operation without the need to connect additional power supplies. The entire boom or its head section are rotated using only a person's muscle power. Low resistance rotation in the central journal, small weight, sufficient length and rotary hinge locks ensure that boom sections can be easily turned by a single person, and precisely located in the required position. A flexible hose is mounted on the second section end of concrete-placing boom to ensure that concrete mixture can be poured into the shuttering or on the floor slab with the highest precision $[3,4]$.

* Corresponding author: KoshkarevEV@mgsu.ru 
Currently, the following types of rotary mechanical booms are produced:

1. With the head section rotating up to $160^{\circ}$ relative to the root section, in both directions of the horizontal plane; the boom is supported by a fixed three or four-post frame via the slewing ring.

2. With the head section rotating up to $160^{\circ}$ relative to the root section, in both directions of the horizontal plane, and capable of lifting vertically to $3-5.5 \mathrm{~m}$.

3. With the head section rotating up to $160^{\circ}$ relative to the root section, in both directions of the horizontal plane; the boom isupported by a column up to $3 \mathrm{~m}$ high mounted on a four-post frame.

Type 1 booms can be installed on a rail [5] track mounted directly on the horizontal reinforcement mesh behind the concreting area. During operation, such booms are fixed on the rails using special clamps. They are moved together with the concreting area, and the track is partially disassembled. Type 1 mechanical concrete-placing booms are used only for concreting horizontal floor slab areas and only when using more complex equipment for supplying the concrete mixture is economically or technically unreasonable, for example, when working on a large area or on a height that exceeds the specifications of the concrete pump truck.

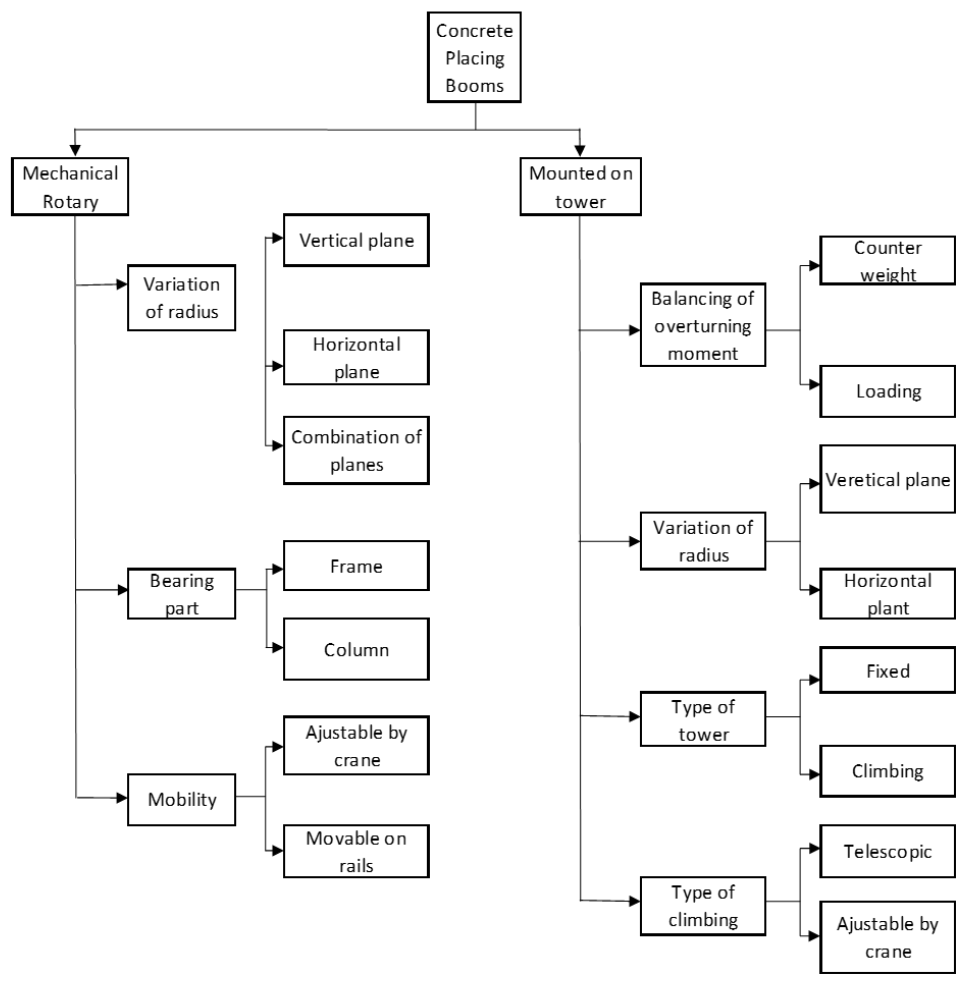

Fig. 1. Classification scheme of stationary concrete placing booms

These booms are produced with an outreach of 6.6 to $15 \mathrm{~m}$, supply height of up to $1.5 \mathrm{~m}$ and can provide a concreting area of up to $700 \mathrm{~m}^{2}$.

Type 2 boom is more versatile, as it allows for pouring the concrete mixture not only on a horizontal surface, [6] but, thanks to its slope, it can be used for constructing store walls and partitions. In this case, the head section is lifted by a hydraulic cylinder using a handoperated pump. Such booms have an outreach of $14 \mathrm{~m}$, lifting height of up to $4.7 \mathrm{~m}$, and a working area covered by one unit of up to $530 \mathrm{~m}^{2}$. 
Type 3 boom is the most versatile, as it provides for concreting not only the walls and columns of a building, but also for concreting below the unit's level if an extended distribution hose is provided, with an outreach of up to $20 \mathrm{~m}$, height up to $7.7 \mathrm{~m}$ and an area of up to $730 \mathrm{~m}^{2}$.

\section{Self-propelled concrete-placing booms}

These booms mounted on a truck or crawler chassis are now used very widely [7]. The classification does not present self-propelled concrete placing booms, because they are all structurally similar.

Concrete pump trucks consist of two main elements: transfer pump with a hopper where the concrete mixture is poured into, and the boom carrying the pipes that supply material into the shuttering with various heights and outreaches. Operation of a concrete pump truck involves frequent change of location, therefore the boom design provides for folding it into the transportation position. for example, when working on a large area or on a height that exceeds the specifications of the concrete pump truck.

Concrete mixture supply booms consist of several sections that are hinged together. This ensures their high maneuverability, good approachability to the mixture placing location, as well as the transportation function. A major benefit of applying concrete pump trucks is that their design includes a screw concrete mixer. After the concrete mixture is loaded into the concrete pump truck hopper, it is maintained in the necessary condition throughout the entire transportation time period and up to the time when concreting is started. The latest models of concrete pump trucks already are equipped with an innovative system for purging the concrete-conveying pipe by means of an air compressor. Maximum supply height of such booms can be up to $66 \mathrm{~m}$, with the outreach of up to $60 \mathrm{~m}$. [7] The height and outreach will hardly be increased further, as it results in certain problems with operating such trucks, namely, difficulties with efficiently controlling the truck when it is moved from one construction site to another, as well as when pouring concrete, and safety issues [8].

\section{Concrete-placing booms mounted on a column, mast or tower}

In recent years these booms have been widely used in cast-in-place construction of highrise structures, with large area and complex configuration, together with stationary concrete pumps $[9,10]$.

This machine allows for continuously supplying the concrete mixture without wasting time for concrete loading and lifting. The mixture may be lifted and continuously discharged in the required location while the structure is being built-up vertically and horizontally [11]. The machine is capable of supplying an area with an outreach of 50 meters and more without the need to move the equipment in the horizontal direction. If it is necessary to change the height of concrete mixture supply, the crane mast can be extended fairly quickly by means of telescoping, even when complex-shaped constructions are built, for example, oval or polygonal [1]. It is this type of booms that was used for building the tallest concrete structure in the world, Burg Khalifa Dubai sky-scraper, and is being used now in the project of Kingdom Tower in Jeddah, Saudi Arabia, 1,000 m high, where as many as 3 booms type SPB35 and 2 booms type SPB30 are installed simultaneously [12].

Globally, over 30 boom models are manufactured. However, if one takes into account the modifications in terms of mast height and cross-section, its telescoping method, the method of fixing the mast to the building's structure, the actuator type of boom rotation mechanism, the method of boom folding and unfolding, this number will be even greater. 
Currently, despite some difference in concepts, a certain stereotype has been formed for designing these machines. The machine has a load-bearing part that is essentially either two crossing beams (cross-piece) or three beams connected to each other at an angle of $120^{\circ}$. The load-bearing part is fixed by means of anchor bolts, either to a dedicated foundation, or to building floor slab. An alternative option for immobilizing is possible, using counterweights to surcharge the ends of each load-bearing beam $[13,14]$.

The load-bearing part is used to install the mast or tower that may be essentially a solid pipe (round, square, hexagonal or octagonal) or mesh, if the height is between 10 and $45 \mathrm{~m}$ [5]. During operation, the mast can be extended by telescoping, as it is provided in its design. The telescoping mechanism can be designed as a rack-and-pinion, or using a hydraulic cylinder (more common). The telescoping speed is $0.5-0.8 \mathrm{~m} \backslash \mathrm{min}$ regardless of the method. The tower is passed through building floors using either engineering equipment openings (elevators, cable shafts, etc.), or dedicated openings are provided that are subsequently sealed by cast-in-place concrete. For heights up to $20 \mathrm{~m}$, the mast is freestanding. For greater heights, it is supported by a mounting frame, installed on the floor slab and fixed to it using through bolts [15].

The tower's top section contains a swivel head with the boom and concrete-conveying pipe installed on a crown. The crown provides for an average rotation rate of $0.4-0.5 \mathrm{rpm}$ in the horizontal direction. The angle of rotation is typically up to $370^{\circ}$, and with some manufacturers, it is $570^{\circ}$. Further rotation is limited by the concrete-conveying pipe. The crown is selected based on the static load and bending moment that it is exposed to, taking into account the dynamic factor. Boom rotation mechanism is installed on a special platform that is rigidly connected to the mast. Its actuator can be either electrical or hydraulic. Hydraulic actuators are preferable, because the boom extension mechanism can be only hydraulic, hence a hydraulic pack is always present. The hydraulic pack is not loaded during the boom rot)ation, and it is not sensible to use two types of energy.

Crane boom typically consists (regardless of outreach) of 3-5 sections that are rotated relative to each other using hydraulic cylinders [3]. If four sections are used, the maximum rotation angle of the first section relative to mast centerline is $82-93^{\circ}$, the angle of the second section relative to the first, on average, is $180^{\circ}$, the angle of the third section relative to the second is $180-245^{\circ}$, and the angle of the fourth section relative to the third is 240 $250^{\circ}$. The ratio of section lengths is maintained, on average, as 1.1:1:1:0.95.

The distribution hose on the boom is typically 3-4 $\mathrm{m}$ long. This ensures sufficient ease of controlling it when placing concrete mixture, despite its rigidity and counter torque.

It should be noted that stationary mast booms are divided into two types depending whether a boom counterweight is used or not [16]:

- without counterweight jib;

- with counterweight jib.

In order to define the borderline between the two above-mentioned types, information on both machine types that are currently being manufactured has been collected. This information was summarized in a table (not included in this article). Similar to other boomtype cranes used in construction, the main comparison parameter was defined as the outreach of concrete mixture supply rubberized hose that always hangs vertically regardless of boom position and configuration [6].

Concrete mixture supply outreach is the distance between the axis of rotating boom section rotation and the hose centerline, horizontally measured. By analyzing the series of specifications for various manufacturers in terms of maximum outreach, it was revealed that booms with an outreach of $28-36 \mathrm{~m}$ are the most common $(48.27 \%)$. The second important group is machines with an outreach of 16 to $24 \mathrm{~m}(27.58 \%)$, and a slightly smaller group is machines with an outreach of $36-52 \mathrm{~m}(24.15 \%)$. The working area of up 
to $16 \mathrm{~m}$ is mainly served by rotary booms that have gained new momentum in recent years, while the working area of over $52 \mathrm{~m}$ is preferable for booms installed on tower cranes.

\section{Conclusions}

Statistical analysis has also revealed that starting from the outreach of 24 meters, a counterweight installed on a dedicated jib can be used in the boom. In case of machines without counterweight, the crown diameter and tower cross-section dimensions are significantly increased due to much higher moment created by unbalanced masses: the boom, concrete-conveying pipe and the concrete mixture it contains. This is especially important for free-standing booms where the dimensions of mesh tower are dramatically increased from a standard square of $750 \times 750 \mathrm{~mm}$ to $1,500 \times 1,500 \mathrm{~mm}$. Notably, $66.66 \%$ of machines with a jib have an outreach of over $32 \mathrm{~m}$, and half of those are machines with an outreach of over $44 \mathrm{~m}$. Therefore, the most probable border line for jib installation on a boom can be considered as $36 \mathrm{~m}$.

\section{References}

1. S.N.Alekseev Nasosnyj transport betonnoj smesi. p.15 (1952)

2. R.D Browne, P.B. Bamforth Tests ACI Journal, vol. 74, p. 193-195 (1977)

3. A.N.Ede Magazine of Concrete Research, no. 9, p. 129-132 (1957)

4. F.Chapdelaine Thèse présentée à la Faculté des études supérieures de l'Universite de Laval, p. 98 -104, Quebec, Canada ( 2007)

5. M.Sakuta, I. Kasanu, S.Yamane, A.Sakamoto Pumpability of fresh concrete, p. 22, Tokyo (1989).

6. T.T.Ngo Ph.D. dissertation, p. 52-58, Cergy Pontoise, France (2009.)

7. T. G. Hicks Handbook of Mechanical Engineering Calculations, Second Edition, McGraw-Hill Education p. 112-115 (1998)

8. GOST 6540-68 (Standard of URSS) Hydraulic and pneumatic cylinders. Ranges of basic parameters

9. ISO 21573-1/2006 Building construction machinery and equipment. Concrete pumps. Part 2. Procedure for examination of technical parameters

10. M.F.Uvarov, M.A.Stepanov, E.V.Koshkarev Mashiny dlya tekhnologicheskogo transportirovaniya stroitelnyh materialov I izdelij - M.: MGSU EBS ASV, p.155-156 (2013)

11. E.V.Koshkarev, V.I.Skel, V.A.Christoforov Mechanization of construction, no.11 p. 18-19 (2014).- p. 18-19

12. M.A.Stepanov, P.A.Iljuhin Mechanization of Costruction. no.11 p. $54-57$ (2016)

13. Hongbin Tang. Wu Ron Advanced Mechanic Engineering no.9 (2015).

14. MILOP Design and Consulting Pty, Ltd // Concrete Placing Booms Mounted on Tower http://milop.com.au/Index TowerBooms.html

15. E.V.Koshkarev, K.S.Stebunova Mechanization of Costruction. V.845, no.11 p. 5254(2016)

16. Ye.Koshkarev Conference Proceedia Ingineering p.1684-1688 doi 10.10/16.j/proewng (2017) 